\title{
Living related renal transplantation from grandparental donors to paediatric recipients
}

\section{Stephen Marks}

M Scanes, J Tanton, K Knapp, A Copley, C Gaymer, $S$ Boyle, W Hayes, $N$ Kessaris, $N$ Mamode

Great Ormond Street Hospital for Children and UCL GOS Institute of Child Health, London, UK

IPTA $9^{\text {th }}$ Congress, Barcelona, 29 May 2017 
The greatest gift a parent can give a child during all the ups and downs of life is love.

- Doc Childre - 
The greatest gift a parent can give a child during all the ups and downs of life is love.

Grandparents give the greatest gift of all... UNCONDITIONAL LOVE 


\section{Case history}

- 10 year old girl

- ESKD on PD ?cause

- Maternal grandfather aged 50 years

- Out of centre referral as donor multiple vessels

$-3 R+3 L$ renal arteries

- UTI at 1 month

- $\mathrm{PCr}=56(\mathrm{eGFR}=95)$

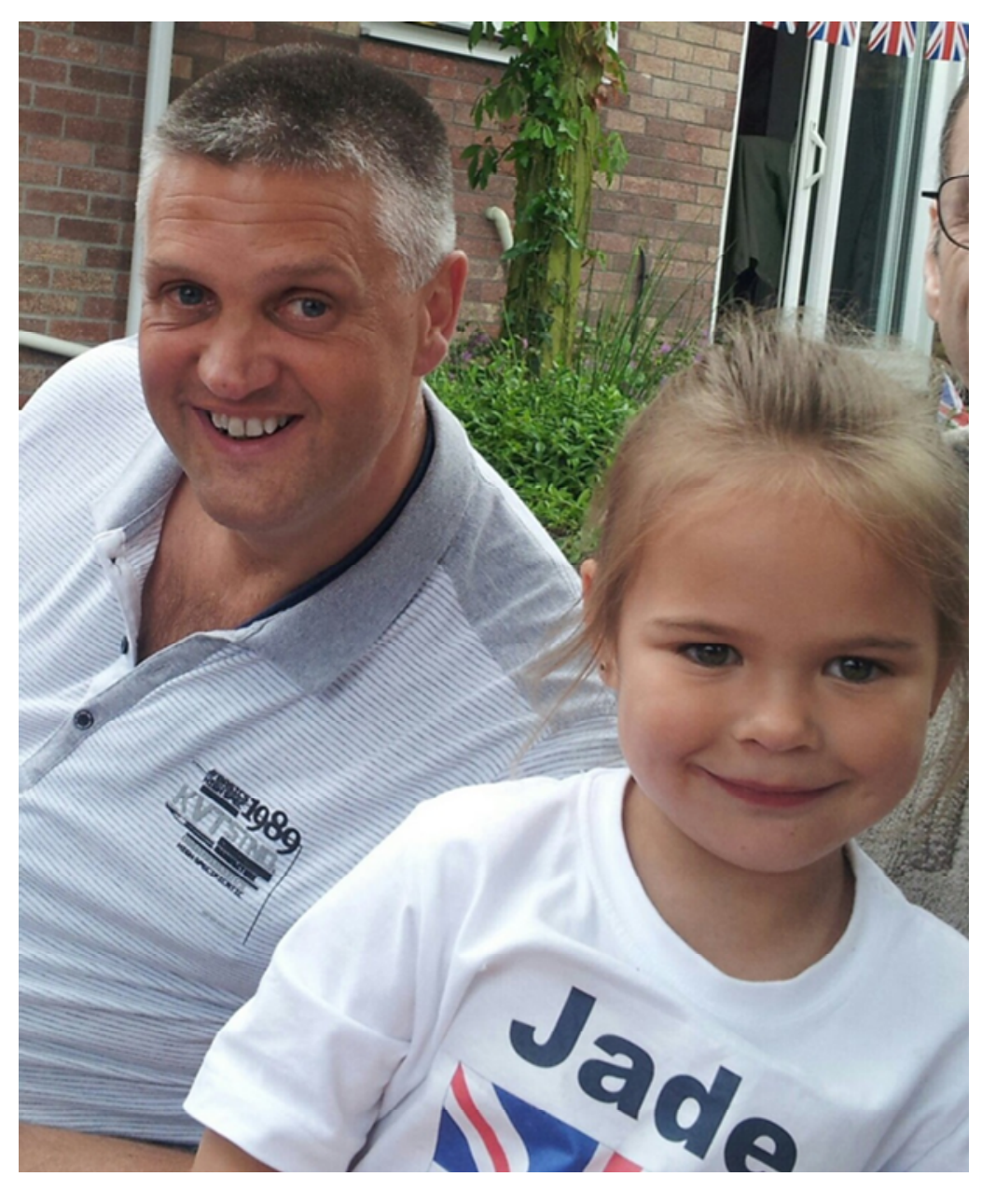




\section{Paediatric recipients}

- 7 children

- between 8 September 2009 and 2 May 2017

-4 girls ( $57 \%$ ); 3 boys (43\%)

$-\mathrm{PCr}=353-526 \mu \mathrm{mol} / \mathrm{l} ; 2$ retransplanted

- aged 2.1 - 11.7 (median 6.9) years at transplant

- weight of 10.8 - 46.9 (median 16.8) kg

- 4 INTRAPERITONEAL (UNDER 20kg)

- 4 outside referrals of complex cases

- 2 COMPLEX RECIPIENTS "UNTRANSPLANTABLE"

- 1 COMPLEX DONOR ANATOMY 


\section{Cause of ESKD}

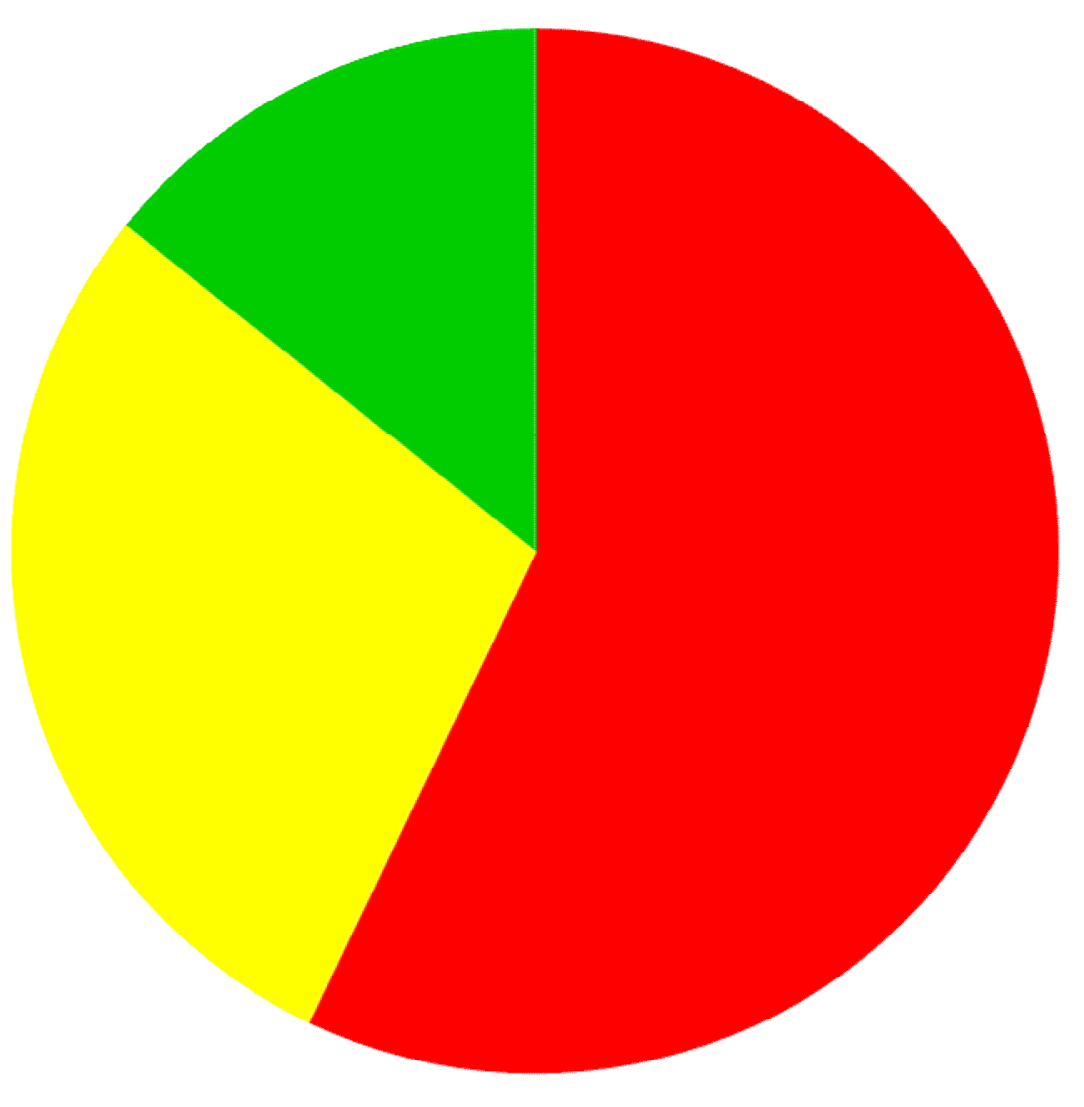

$P U V=1$
CAKUT Cloaca=1 FSGS/CNS - HIV 


\section{Modalities of ESKD}

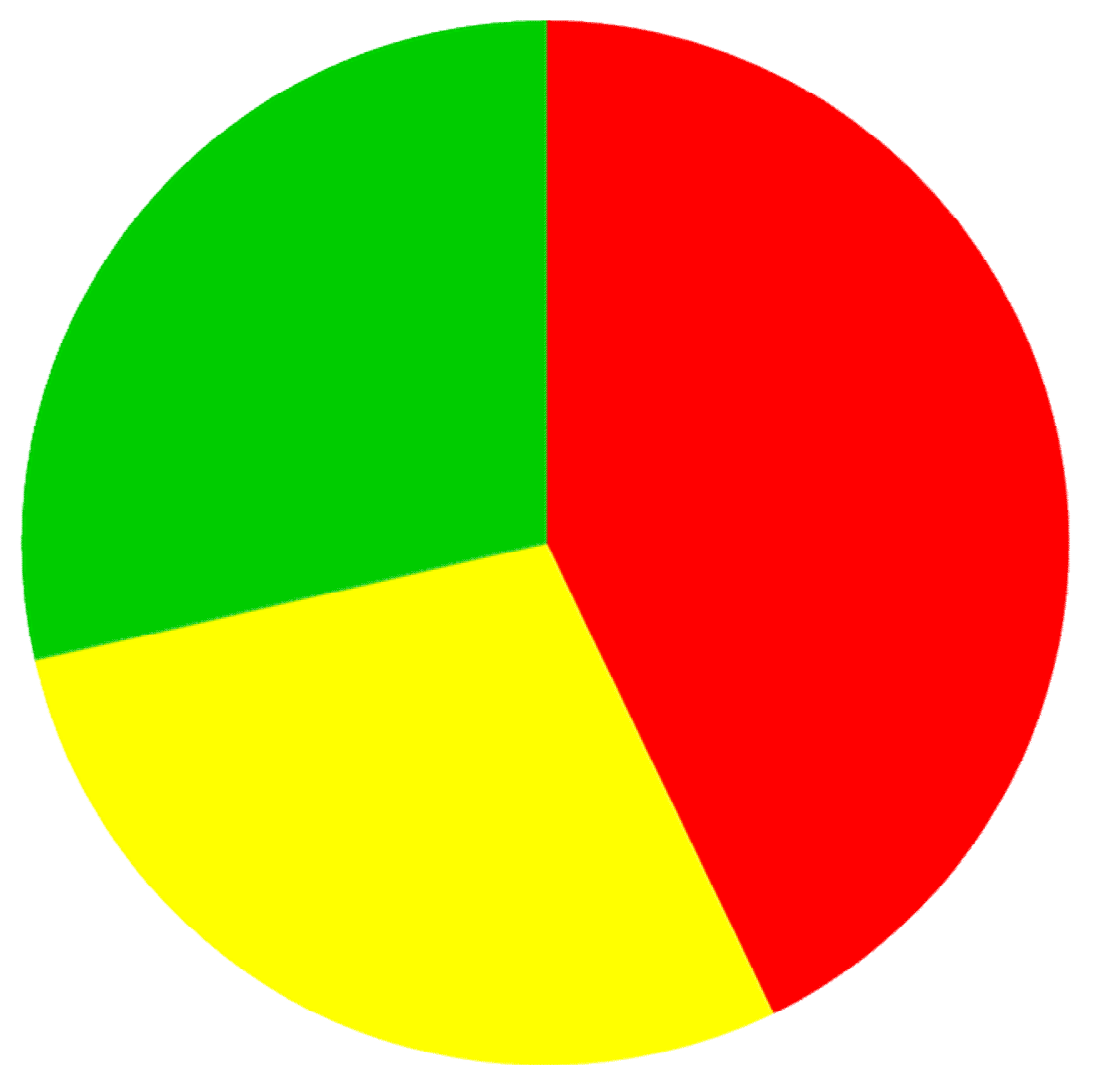

- Pre-emptive

HD

- PD 


\section{Grandparental donors}

- 5 grandmothers $(71 \%)$

- 2 grandfathers (29\%)

- aged = $45-56$ (median 50) years

- eGFR = 72 - 89 (median 84) $\mathrm{mls} / \mathrm{min}$

- all blood group compatible:

- 4 O DONORS TO O RECIPIENTS

- 3 O DONORS TO A RECIPIENTS

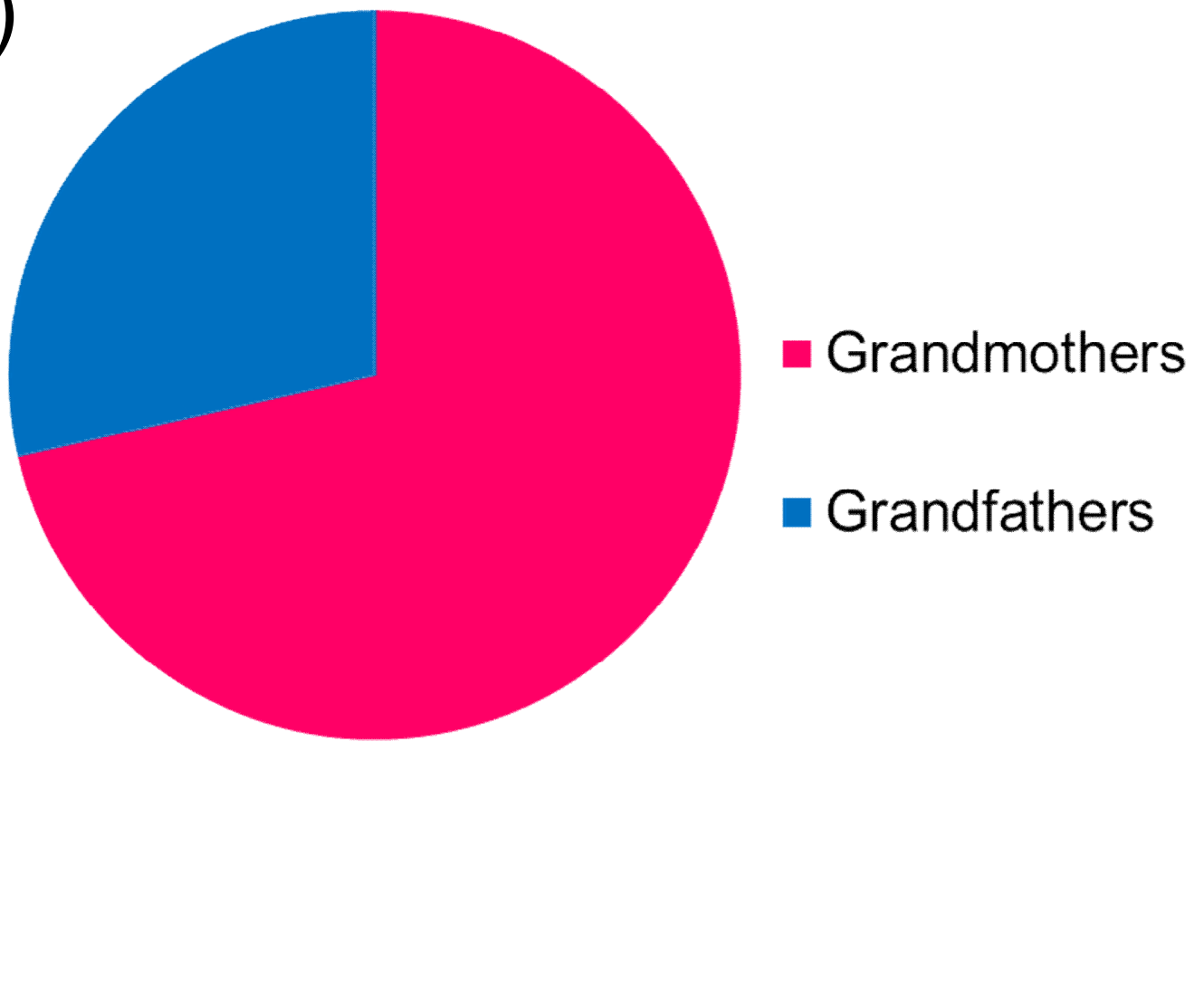




\section{Mismatches}

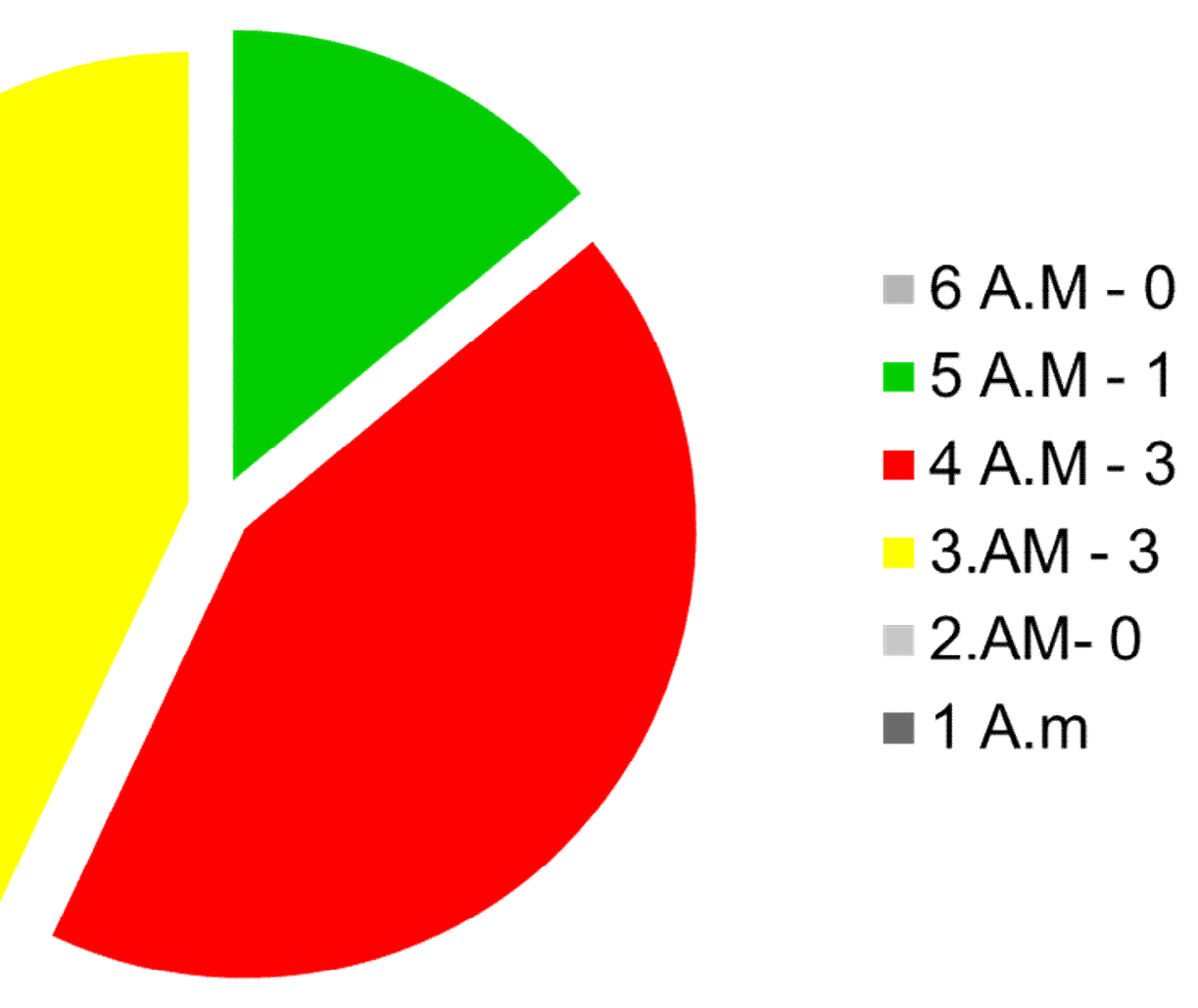




\section{Why did the grandparents donate?}

- 2 families wanted to use parents for subsequent LRD in future

- 2 psychosocial issues

- father in prison, mother drug addiction, child protection issues and child cared for by grandmother (donor)

- mother psychological issues, father absent; child cared for by grandmother (donor)

- 2 patients had failed parental LRD

- other parent medically unsuitable

- 1 parent medically unsuitable; absent father 


\section{Recipient follow up}

- Post-transplant follow-up

- 1.0 months - 7.5 years (median 2.8 years)

- $100 \%$ patient survival

- $86 \%$ renal allograft survival

- retroviral disease

- Good renal allograft function

- plasma creatinine of $56-92 \mu \mathrm{mol} / \mathrm{I}$

- eGFR of $52-83 \mathrm{mls} / \mathrm{min} / 1.73 \mathrm{~m}^{2}$ 


\section{No acute rejection episodes}

- 4 biopsies performed in 3 patients

- no rejection

- mild chronic changes 


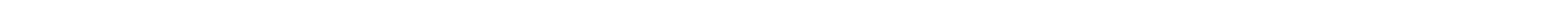




\section{Conclusions}

- Excellent patient and renal allograft survival with grandparental donors

- Improved outcomes

- psychosocial input

- post-transplant psychological evaluation 


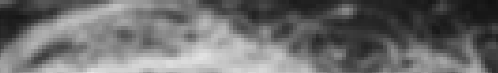

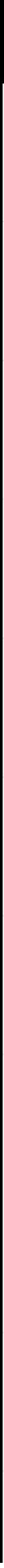

